\title{
Digital Models In Construction: Classification Paradigm
}

\author{
Andrey Volkov* \\ Moscow State University of Civil Engineering, Yaroslavskoe shosse, 26, Moscow, 129337, Russia
}

\begin{abstract}
The new tasks of the country's development determine the special significance of the academic and professional community of the construction industry in deep understanding and active participation in the processes of traditional transformation and the formation of new areas of competence. Creation, facilities and infrastructure, urban environment become today a main area of intersection and concentration of high-tech areas of scientific progress. The article considers an original scheme of system engineering for digital modeling of creative activity are presented. Within the framework of the scheme, seven levels of digital modeling, corresponding to six levels of aggregation of links: «plan» - «goal», «object» - «project», «process» - «time», «technology» - «economy», «system»- «resource», «complex»- «convergence» are described.
\end{abstract}

\section{Digital Models}

The program "Digital Economy of the Russian Federation", approved by the Government Decree of the Russian Federation of 28/07/2017, No. 1632-p, defines the following main point-to-point digital technologies [7]:

- bulk of data;

- neurotechnologies and artificial intelligence;

- distributed ledger systems;

- quantum technologies;

- new manufacturing technology;

- industrial Internet;

- robotics components and sensory;

- wireless communication technology;

- virtual reality and augmented reality technology.

At the same time it was pointed out that the above list of technology is not exhaustive, but may be changed as new technologies develop. However, it is obvious that its initial version also forms a significant number of intersections of virtually all component directions in the above mentioned "smart city" paradigm. The above mentioned is in fact

\footnotetext{
* Corresponding author: ChelyshkovPD@mgsu.ru
} 
confirmed by a reference to a specific direction of "creating smart cities" [7] as a priority, prospectively supplementing the program with a corresponding section and a "road map" on the first pages of the program [7] completing the list of end-to-end technologies.

Therefore, in order to form a fair view of the development prospects of digital modeling in creative activity, it is absolutely necessary to perform an analysis of a new domain area at the level of determining its constituent elements and structural connections. I am confident that this will massively simplify the understanding of the emerging "digital" trends in the development of the real sector of the construction industry in the new understanding of its professional responsibility, not only by experts, but also by managers of various levels, whose competence today actually determines the innovative potential of any enterprise within the entire scope of work. The objective in this context is more than timely, because there are very few attempts of such analysis today, most of which are not academic, but represent a private initiative of individual practitioners or their associations of various properties forced to independently form strategic and tactical "digital" benchmarks of their own business, to objectively evaluate and integrate into a fairly rapidly changing technological and economic model, as well as the system of regulation of the industry and/or, in case of representatives of companies - software developers - to substantively present the promotion of their products.

Further, the author presents his own view on the systems engineering [6] of digital modeling of creative activity (fig. 1).

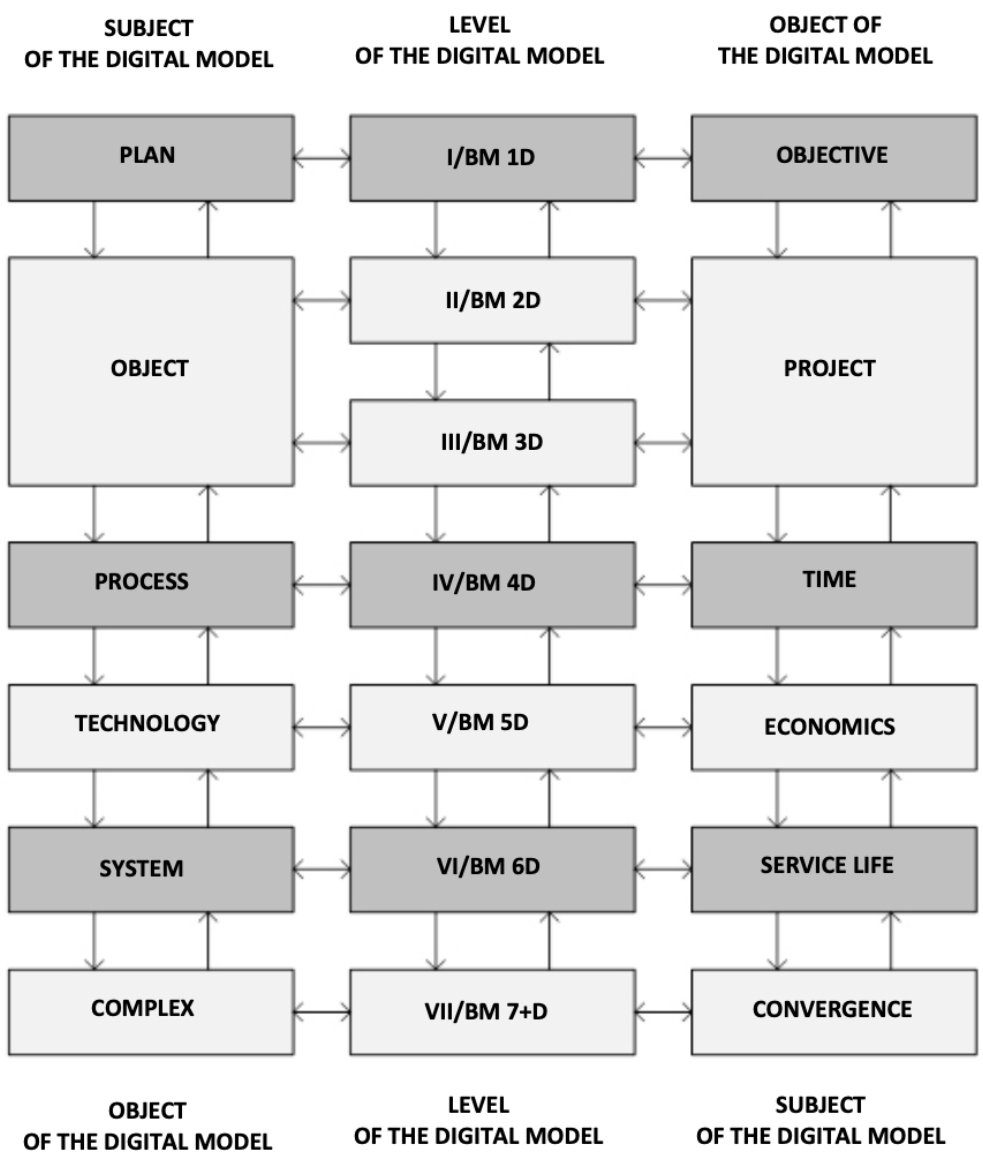

Fig. 1. Systems engineering of digital modeling in creative activity 
The presented logical and conceptual scheme in the cybernetics paradigm of problemoriented modeling abstractly highlights the main subject-object (object-subject) horizontal communication of the constituent elements, each pair of which is determined to correspond to their own level of digital modeling.

At the first (I) level of digital modeling of subject-object connections (the top line of names of verticals of subjects and objects is given in fig. 1), various aspects of the motivational component of the activity, that establish a direct correspondence of a certain set of plans to a certain set of goals, are formalized, often by simple arbitrary or fixed format description. An object-subject feedback implies the effect of target correction on the plans for their execution, and the conditionally symmetric subject-object connection (the bottom line of the names of the verticals of objects and subjects is given in fig. 1) changes the priority pattern to the inverse - a set of objectives corresponds to a number of plans.

For the conceptual simplicity of the general logic of the scheme, the presented system engineering of digital modeling of creative activity establishes a conventionally direct correspondence of the levels of digital modeling to the levels of the BIM dimensions. So, the first (I) level of digital modeling corresponds to the first (1D) level of the BIM dimensions.

In a similar manner, the logic of the system design of digital modeling of creative activity implies seven levels that correspond to the six levels of aggregation of subject matters in terms of subject-object (object-subject) connections: "plan" - "objective", "object" - "project", "process" - "time", "technology" - "economics", "system" "resource", "complex" - "convergence".

At the second (II) and at the third (III) level of digital modeling of subject-object connections in the project, two- and three-dimensional models of some object of creative activity are formalized, respectively. Object-subject feedback implies the influence of a set of conditions and design constraints on the object itself, and the conditionally symmetric subject-object connection changes the matching priority pattern to the feedback when the object is created based on the design priority set on any basis (for example, using a typical project). It should be noted that the subject matter of the "object" - "project" of the second (II) and the third (III) level of digital modeling is not limited to two- and three-dimensional visualization of the object, but is the basis for automation and optimization of version design, design and intelligent parameterization of the project.

The second (II) and the third (III) level of digital modeling is determined by the second (2D) and the third (3D) level of the BIM dimension, respectively.

At the fourth (IV) level of digital modeling of subject-object connections, the processes that constitute creative activity are formalized by the time they need. Object-subject feedback implies the influence of temporal conditions and constraints on the processes under consideration, and the conditionally symmetric subject-object connection changes the correspondence priority scheme to reverse, when a set of processes is formed based on the conditions and time constraints (for example, fixed time limits for object infrastructure commissioning). The subject matter of the "process" in the scheme aggregates their exhaustive formulation of a specific task set (production, organizational, management processes, etc.).

So, the fourth (IV) level of digital modeling corresponds to the fourth (4D) level of the BIM dimensions.

At the fifth (V) level of digital modeling of subject-object connections, technologies used in creative activity are formalized by estimating the value of their use. Object-subject feedback implies a direct impact of economic conditions and restrictions on the technologies used, and a conditionally symmetric subject-object connection changes the compliance priority scheme to feedback when technological schemes are formed based on 
financial conditions and restrictions (for example, availability of a particular process equipment).

The fifth (5D) level of the BIM dimensions corresponds to the fifth (V) level of digital modeling.

At the sixth (VI) level of digital modeling of subject-object connections, the objects, processes and technologies constituting the building systems are formalized by the aggregation of all types of resource support for creative activities presented at previous levels of digital modeling by economics and time. The object-subject feedback implies the influence of resource conditions and restrictions on the systems under consideration, and the conditionally symmetric subject-object connection changes the compliance priority scheme to feedback, when the building system itself is formed based on conditions and resource constraints (for example, construction under the conditions of disruption of supplies of materials or lack of qualified personnel). The subject-matter of the "system" in the scheme corresponds to the definition of a "building system" as a finite set of functional components (elements, objects, construction complex) and their connections, selected in accordance with a specific goal within a certain time frame [3]. The subject matter of "resources" is aggregated by their exhaustive formulation of a specific task set (material, technical, labor, organizational, etc.).

The sixth (VI) level of digital modeling corresponds to the sixth (6D) level of the BIM dimensions.

At the seventh (VII) level of digital modeling of subject-object connections, building systems that make up creative activity are combined into complexes that include additionally qualitatively different systems (for example, social or biosphere [6]) and make up the object of digital modeling of a new class in terms of convergence. The object-subject feedback implies the influence of qualitatively different systems with respect to construction systems on the complexes in which they are considered, and the conditionally symmetric subject-object communication changes the priority scheme to reverse, when quality systems are significantly different affect the complexes of building systems without regard to their positioning with respect to the complex under consideration (for example, the influence of the geopolitical situation on the course of dependent construction projects). It should be particularly noted that the analysis and solution of most of the tasks of the above mentioned new stage of creative activity (stage 4 in fig. 1) is formalized in terms of convergence precisely at this level of digital modeling.

The seventh (VII) level of digital modeling defines the expanded seventh (7+D) level of the BIM dimensions, including a further abstraction of any next level of digital modeling, qualitative convergence of constituent systems of various properties $(8 \mathrm{D}, 9 \mathrm{D}, \ldots, \mathrm{ND})$, objectively limited, however, by current status scientific and technical and social progress of society, on the one hand, and objectivity of necessity and elementary common sense, on the other hand.

Any scaling of I-VI levels of digital modeling and the corresponding levels of BIM dimensions is currently objectively exhausted by the framework of six available levels of aggregation of entities in terms of subject-object (object-subject) connections: "plan" "objective", "object" - "project", "process" - "time", "technology" - "economics", "system" - "resource", "complex" - "convergence".

All the levels of digital models of the presented system engineering of creative activity are connected on object basis, on subject basis, and, in fact, on the logic of digital models, voluntarily.

Any designated level of digital modeling of creative activity is open for establishing connections with digital modeling systems external to the complex under consideration (for example, weather forecasting). 
It is curious that the described approach to building subject-object and object-subject direct connection and feedback (see fig. 1) at the model level allows for a correct understanding of the subject matter and revision of emphasis in many completely practical areas of innovative development and regulation of the industry. For example, some differences in the assessment of resource, resource-index, basic-index and basiccompensatory methods for determining the estimated cost of construction are well clarified.

Summarizing the presented logical and conceptual scheme as a whole, it should be noted that it is the paradigm of the subject matter "complex" - "convergence" which includes the main challenges of scientific-and-technical advance to the traditional understanding of the industry [1-5,8-13] and at the same time the quality effects of progress in creative activity for the upcoming next 25 years.

\section{Conclusions}

1. An original system layout of digital modeling of creative activity is proposed. The layout describes seven levels of digital modeling that correspond to six levels of links formation: "plan" - "objective", "facility" - "project", "process" - "time", "technology" "economics", "system" - "resource", "complex" - "convergence". All levels of digital models of the presented system engineering of creative activity are connected on object basis, on subject basis, and, in fact, on the logic of digital models, voluntarily.

2. Summarizing the presented logical and conceptual scheme as a whole, it is noted that it is the paradigm of the subject matter "complex" - "convergence" which includes main challenges of scientific-and-technical advance to the traditional understanding of the industry and at the same time the quality effects of progress in creative activity in the horizon of the next few decades.

This work was financially supported by Ministry of Science and Higher Education of the Russian Federation (\#NSh-3492.2018.8).

\section{References}

1. A. Volkov "Smart buildings" - "smart city": from practice to theory J. Automation of buildings. 5. 2006.

2. A. Volkov Intelligence of buildings: formula J. Industrial and civil construction. 54-57, 3. 2012.

3. A. Volkov Cybernetics of the building system. Cyber physical building systems J. Industrial and civil construction. 4-7, 9. 2017.

4. A. Volkov Smart City: Convergent Socio-CyberPhysical Complex. J. Industrial and Civil Engeeniring, 4-11, 9. 2018.

5. V. Ilichev, V. Kolchunov, N. Bakaeva Training of experts in architectural and construction industry on the basis of the paradigm of biospheric compatibility $\mathrm{J}$. Industrial and Civil Construction. 9-17, 9. 2017.

6. Systems engineering / Edited by A. A. Gusakov. (M.: New millennium Foundation. $768,2002)$

7. Digital economics of the Russian Federation, Program. Government Decree of the Russian Federation dated 28/07/2017, No. 1632-p. 87 P. Electronic source: URL http://static.government.ru/

8. P. Chelyshkov Aspects of computer-aided design of cyber-physical building systems J. Industrial and Civil Construction. 21-27, 9. 2018.

9. Volkov, A. Application of computer simulation to ensure comprehensive security of buildings / A. Volkov, P. Chelyshkov, A. Sedov // Applied Mechanics and Materials. - 
V. 409-410 (2013). - pp. 1620-1623. - doi:10.4028/www.scientific.net/AMM.409410.630

10. Volkov, A. Usage of building information modelling for evaluation of energy efficiency / A. Volkov, A. Sedov, P. Chelyshkov // Applied Mechanics and Materials. - 2013. - V. 409-410. - pp. 630-633. - doi:10.4028/www.scientific.net/AMM.409-410.630

11. Volkov, A. Modeling the thermal comfort of internal building spaces in social buildings / A. Volkov, A. Sedov, P. Chelyshkov // Procedia Engineering. - 2014. - V.91. - pp. 362-367

12. Volkov, A. Using CAD for selecting different ACS engineering systems of buildings and structures in the presence of interference and restrictions / A. Volkov, A. Sedov, P. Chelyshkov, A. Doroshenko // Applied Mechanics and Materials. - 2014. - V. 580583. - pp. 3231-3233. - doi:10.4028/www.scientific.net/AMM.580-583.3231

13. Volkov, A. Modeling the thermal comfort of internal building spaces in hospital / A. Volkov, A. Sedov, P. Chelyshkov, E. Kulikova // Applied Mechanics and Materials. 2014. - V. 584-586. - pp. 753-756. - doi:10.4028/www.scientific.net/AMM.584586.753

14. Volkov, A. Modeling the thermal comfort of internal building spaces in kindergarten / A. Volkov, A. Sedov, P. Chelyshkov, E. Kulikova // Applied Mechanics and Materials. - 2014. - V. 584-586. - pp. 757-760. - doi:10.4028/www.scientific.net/AMM.584586.757

15. Volkov, A. Modeling the thermal comfort of internal building spaces in school / A. Volkov, A. Sedov, P. Chelyshkov, E. Kulikova // Applied Mechanics and Materials. 2014. - V. 584-586. - pp. 761-764. - doi:10.4028/www.scientific.net/AMM.584586.757

16. Volkov, A. The theory of probabilities methods in the scenario simulation of buildings and construction operation / A. Volkov, A. Sedov, P. Chelyshkov, B. Titarenko, G. Malyha, E. Krylov // Research Journal of Pharmaceutical, Biological and Chemical Sciences. - 2016. - No. 7(3). - pp.2416-2420

17. Volkov, A. Promising energy and ecological modeling in computer-aided design / A. Volkov, A. Sedov, P. Chelyshkov, A. Pavlov, L. Kievskiy // International Journal of Applied Engineering Research. - 2016. - V. 11. - No.3. - pp. 1645-1648

18. Sedov, A. The analysis of expediency of daylight sensors using by application of the combined strategy of artificial lighting management / A. Sedov, P. Chelyshkov, A. Afanasev, M. Vainstein, Y. Vilman, Y. Grossman // Research Journal of Pharmaceutical, Biological and Chemical Sciences. - 2016. - No. 7(2). - p. 1046-1053

19. Volkov, A. Information management in the application of BIM in construction. The roles and functions of the participants of the construction process / A. Volkov, P. Chelyshkov, D. Lysenko // Procedia Engineering. - 2016. - V. 153. - pp. 828 - 832

20. Volkov, A. Information management in the application of BIM in construction. Stages of construction / A. Volkov, P. Chelyshkov, D. Lysenko // Procedia Engineering. 2016. - V. $153 .-$ pp. $833-837$

21. Shirokov, L. Automated management of engineering infrastructure of pools of different function / L. Shirokov, P. Chelyshkov, E. Romanenko // MATEC Web of Conferences 86, 04062. - 2016. - DOI: 10.1051/matecconf/20168604062

22. Volkov, A. BIM cost analysis of transport infrastructure projects / A. Volkov, P. Chelyshkov, Y. Grossman, A. Khromenkova // IOP Conf. Series: Earth and Enviromental Science 90 (2017) 012203. - 2017. - doi: 10.1088/1755$1315 / 90 / 1 / 012203$

23. Chelyshkov, P. Use of BIM in Design of Standarrd Facilities / P. Chelyshkov, D. Lysenko // International Journal of Applied Engineering Research Volume 12. - 2017. No. 24. - pp. 15119-15121 
24. Andreeva, A. Management of parameters of the functioning of engineering systems of the building object based on algorithmic data analysis / A. Andreeva, P. Chelyshkov // IOP Conference Series: Materials Science and Engineering. - 2018. - V. 365. 022041. - doi: 10.1088/1757-899X/365/2/022041

25. Lysenko, D. The method of optimization of energy-efficient engineering solutions by varying criteria in CAD / D. Lysenko, P. Chelyshkov // IOP Conference Series: Materials Science and Engineering. 2018.- V. 365.- 022027. doi: 10.1088/1757899X/365/2/022027

26. Galkina, E., Kuzina, O. Building information model verification at the lifecycle stage of construction //Volume 365, Issue 6, 2018, 062031, 21st International Scientific Conference on Advanced in Civil Engineering: Construction - The Formation of Living Environment, FORM 2018.

27. Ginzburg, A., Kuzina, O., Ryzhkova, A. Unified resources marking system as a way to develop artificial intelligence in construction // Volume 365, Issue 6, 2018, Номер статьи 062021, 21st International Scientific Conference on Advanced in Civil Engineering: Construction - The Formation of Living Environment, FORM 2018. 